\title{
The Tangled Mesh of Words and Worlds: The Inbetweenness of Language in the Literature Classroom
}

Ananya Dutta Gupta

\begin{abstract}
This essay examines the imperatives of the English literature classroom in a non-metropolitan milieu and contends that bilingualism in such a setting is intellectually empowering and helps fashion, in the true spirit of literature, the empathy between the global and the local without which cultural cosmopolitanism is impossible.
\end{abstract}

Key Words: Language proficiency, Indian classroom, bilingualism, text, pluralism, translation

The stark reality of teaching in an at once socioeconomically semi-rural and culturally semi-urban setting has changed my standards for appraising academic merit. I have come to privilege literary sensibility over literary articulacy. I have persuaded myself to see reticence caused by language inproficiency or inadequacy as a pardonable disability that does not reflect adversely on the kind of unique "reading" skills that the literature classroom helps inculcate. In the literature classroom, the language acquired through and requisite for formal literature studies is implicitly distinguished from the common communicative skills that are prized in the world outside. In a world where the accidents and vagaries of history have helped some languages to sideline others, where language acquisition is largely contingent upon economic prospect, where disinterested mastery of any language, even one's vernacular, is largely a wistfully deferred goal, where lapse and error and deviation have somehow been historicized in terms of a natural progression or 
regression of a language towards either proliferation or extinction, my own imperfect command over my acquired, first language, English, has made me more consciously indulgent towards those who have had significantly smaller scope for acquiring it and are nevertheless attracted towards pursuing degree studies in the literatures available in that language. Grammatical standards are as fluid and contingent upon quirks of subjective usage, particularly at moments of accelerated global contact and exchange, as to render stringency problematic.

My second rationale for cultivating such relativism on the question of language proficiency draws upon my own by no means linear but perennially ongoing process of language acquisition. It is true that children who come up to college or university with a pre-acquired proficiency are at a distinct advantage. However, this same advantage may be viewed as a disadvantage if it has been acquired at the expense of her vernacular language and culture. I do not say this from any sentimentalism. The nature of cultural and literary enquiry in academics globally today and, therefore, in today's globalised India no less, is such as to empower multilingual or at least bilingual human resources more readily, more flexibly, more creatively than a monolingual one. So that, the Nepali-speaking student in my department who is also fluent in English and has picked up Bangla over a year or two spent in Birbhum is likely to have more to offer to an ethnographically oriented cultural studies department interested in reaching out to and translating long-neglected and marginalized language and culture spheres of India. An elite English-speaking student with an exclusively metropolitan upbringing with relative discomfort in her vernacular is likely to have a narrower field of play.

For that matter, literature academics of past generations, those who had gone to school in colonial or post-colonial Kolkata and Bengal, had been naturally bi- or trilingual in terms of their cultural universe. A late professor of Jadavpur University, Visvanath Chatterjee, and I am sure there were and are still many like him, was linguistically empowered by his education to straddle Shakespearean drama, Sanskrit literature and Greek 
poetry effortlessly. So, I do not think English literature studies as a formal university discipline was ever monolingual in the truest sense of the term. In Provincialising Europe, Dipesh Chakrabarty (4-5) rues the way in which post-colonial India had continued to assimilate European thought into its cultural discourse to the neglect of its own cultural ancestry:

Faced with the task of analyzing developments or social practices in modern India, few if any Indian social scientists or social scientists of India would argue seriously with, say, the thirteenth-century logician Gangesa or with the grammarian and linguistic philosopher Bartrihari (fifth to sixth centuries), or with the tenth- or eleventh-century aesthetician Abhinavagupta. Sad though it is, one result of European colonial rule in South Asia is that the intellectual traditions once unbroken and alive in Sanskrit or Persian or Arabic are now only matters of historical research for most-perhaps all-modern social scientists in the region. They treat these traditions as truly dead, as history. Although categories that were once subject to detailed theoretical contemplation and inquiry now exist as practical concepts, bereft of any theoretical lineage, embedded in quotidian practices in South Asia, contemporary social scientists of South Asia seldom have the training that would enable them to make these concepts into resources for critical thought for the present. And yet past European thinkers and their categories are never quite dead for us in the same way. South Asian(ist) social scientists would argue passionately with a Marx or a Weber without feeling any need to historicize them or to place them in their European intellectual contexts. Sometimes-though this is rather rare-they would even argue with the ancient or medieval or early-modern predecessors of these European theorists.

While this continues to be true of many of us to this day, I wonder if the literature classroom of the past had somehow been able to surmount this selective cultural myopia or blindness, and that too by virtue of the very nature of literature. Literature or 
sahitya, which Tagore associated with the preposition, "sahit", has this remarkably self-effacing and unobtrusive way of being with us, keeping us company, infiltrating boundaries, however carefully conserved. Further, what globalisation has made possible and indeed necessary is a greater institutionalisation of this cultural cosmopolitanism, perhaps a more promising way of collectively addressing the lacuna that Dipesh Chakravarty alerts us to and that many, including my own self, are guilty of. On one occasion, in my first undergraduate year at Jadavpur University, My point is that many students of English departments today may be found addressing Dipesh Chakravarty's concern. Today's academic aspirant would be ashamed of disowning her vernacular roots in her academic milieu. Reading Byomkesh stories in Bangla and writing a dissertation on it in English, under the aegis of a nominally English literature department, does not raise eyebrows, nor call for elaborate procedural justification.

I look forward to a time when the Bangla, English, Comparative Literature and other Indian language and literature studies departments are allowed to merge into a Languages, Literatures and Cultures department that will, and I cannot but think in terms of the at once converging and diverging spokes of a moving wheel, afford a genuine pool of exchange of reading skills and insights from all its constituent linguistic and literary loci of specialization.

I often toy with the idea of moving to an IIT in order that I may teach a mixed array of texts, some literary, mostly cultural, to budding engineers whom I can bank upon to communicate with me in more correct English, ask more intelligent questions about the texts, thanks to better reading habits, and challenge me by throwing at me ways of looking at reality that only an exposure to higher studies in science or engineering is able to inculcate. First of all, the extreme specialization towards which competitively structured secondary and even higher secondary education has for some time been moving means that all my affirmative assumptions about the all-round merit of the IIT student may well be belied. The strongest reservation I come up with in this 
intermittent dialogue with myself is that I would not be able to speak to them over any sustained period of time in the kind of language that my reading practices have geared me towards. I would, sooner or later, be assimilated within a technological discourse that privileges precisely the kind of exactitude and monolithic meaning-formation upon which scientific enquiry is founded and which operates through the kind of word-registers that leave texts "closed" rather than "open". I understand that it would be dangerously ignorant to brand scientific discourse as inherently monologic. From Ludwig Wittgenstein to Kurt Goedel to Karl Popper, twentieth century philosophy of science has progressively questioned scientific, even mathematical certitude. However, the plurality or the inscrutability of truth, either historical or scientific, is unlikely to be the axiomatic basis of the undergraduate or postgraduate engineering studies classroom. Engineers need material truths, however theoretically open they might be to the discursive plurality of truth as a concept. That is not to say that I do not, by virtue of my neocolonial burden of debt, value the momentous contribution of the Royal Society of Science in the 1660s towards the fashioning of a functional, modern, transparent English language. I admire the English language of many writers who wrote "scientific" English. But I am concerned here not with functional minimalism as a strategy in the usage of any language but with what I see as the differing philosophies of language informing different knowledge disciplines.

In acquiring one kind of language, I would probably have to leave behind a way of writing, of speaking, that is very empowering and very enlightening within the confines of the literature classroom. I am sure I will also gain something over time to compensate my loss. There would be the comfort of knowing that reason and logic and, maybe, dialectics, can get us, if we combine the pursuit of these with a clearer understanding of the cosmic reality. But, the point, of course, is that the world has and should continue to have room for a rich plurality of language-systems, for mathematical language, for the language of music, for that of the paintbrush, and for that imaginative and 
critical writing. In this, I am inspired by a famous essay by Walter Benjamin, 'The Task of the Translator' in Illuminations (74), where he reminds us how no word in any one language finds an exact equivalent in another. So that, the meaning of "bread" can only be arrived at, cumulatively, out of all near-equivalent variants of that concept in all languages: so, "bread" in English, "Brot" in German, "pauruti" in Bangla, and so on:

Wherein resides the relatedness of two languages, apart from historical considerations? Certainly not in the similarity between works of literature or words. Rather, all supra historical kinship of languages rests in the intention underlying each language as a whole-an intention, however, which no single language can attain by itself but which is realized only by the totality of their intentions supplementing each other: pure language. While all individual elements of foreign languages-words, sentences, structure-are mutually exclusive, these languages supplement one another in their intentions. Without distinguishing the intended object from the mode of intention, no firm grasp of this basic law of a philosophy of language can be achieved. The words Brot and pain "intend" the same object, but the modes of this intention are not the same. It is owing to these modes that the word Brot means something different to a German than the word pain to a Frenchman, that these words are not interchangeable for them, that, in fact, they strive to exclude each other. As to the intended object, however, the two words mean the very same thing. While the modes of intention in these two words are in conflict, intention and object of intention complement each of the two languages from which they are derived; there the object is complementary to the intention. In the individual, unsupplemented languages, meaning is never found in relative independence, as in individual words or sentences; rather, it is in a constant state of flux-until it is able to emerge as pure language from the harmony of 'all the various modes of intention. Until then, it 
remains hidden in the languages.

This is the precisely the kind of inclusiveness that exposure to the languages of literatures fosters and makes imperative.

So, there is a problem of language in the literature classroom beyond the distinction between English and Bengali. It is the difference between the scientist's language and the literary critic's language. There is the further inflection of classroom usage by diachronic difference between the literary critic's language of earlier decades and that of the literary theorist-aspirant today. Those amongst us engaged in literature studies are fascinated by the rich, irreducible multiplicity of language, even the changing language of academic discourse. This fascination is obviously shared by those pursuing, say, social linguistics, and certainly, language trainers. The difference in our respective approaches maybe that of texts used as tools as well as of ultimate discursive/ conclusive objective. For instance, a sociolinguist may study the changing usage of the English language among the youth, using smart phone Whatsapp or Facebook as her data bank. She will probably then go on to apply select statistical strategies to process her data and then analyse them in deference to theoretical texts on socio-linguistics, past and present. Where her language and that of a literature academic might meet would be at a further level, where the broader conclusions they both draw about cultural history will be mediated through a pool of theories of knowledge, culture, politics and society, with de Saussure, Barthes, Bakhtin, and Derrida's philosophies of language, that has closed the gap among disciplines within humanities beyond reversal. Beyond that, though, the literature academic will part ways with the socio-linguist, not just in the proportionate presence or absence of literary or imaginative, as opposed to discursive texts from their respective pools of material, but also the differing ways in which they allow their readings of language cultures to be mediated by the cultural or literary texts from one or more spatio-temporal context that they have sampled.

The language skills prioritised by the literature academic, 
over and above or sometimes in lieu of basic communicative efficiency, are more complex, nuanced, inclusive and relaxed than the grammarian's. At the same time, there is a different kind of rigour to it, an academic slant not in sync with the laxities common in everyday spoken language. Journalese, on the other hand, formalizes the language of the everyday according to a yet different set of norms and objectives. So, the literature academic's rigour, the grammarian's rigour and the journalist's rigour are three distinct fashionings of the same language. One can argue towards further denominations within these broad categories: there is a Statesman brand of English and a Telegraph brand of English within journalistic English. The latter was tellingly brought home to us in our childhood with the help of that flagrantly post-modern, ungrammatical, pop coinage: "unputdownable". The literature academic round the world today is acutely sensitive to these pluralities and varieties or variants in language usage. Indeed, the fluidity of imaginative writing, both in terms of its global variety and spread at any given point of time, and of its mutations and reconfigurations across time, has taught us to accept more than one reality, more than one truth, and by extension, more than one language as the exclusive register in terms of which reality is engaged and truth is conveyed, to be plausible. Engagement with imaginative texts impels a certain expansion of the experiential universe, a certain humility, a slackening stringency over binaries such as right and wrong, good and bad, correct and incorrect, acceptable and unacceptable. I am sure that a mathematician or a physicist or an engineering student at IIT does not have his own unique route to the same spirit of tolerance towards other ways of thinking and being. Our goals may well be identical, but our respective points of departure in analytical enquiry, our methodological routes and our diction choices are happily different. Earlier, I spoke of the not so distant future in Indian academia when multiple literature and language departments merge under one overarching umbrella. For genuinely pathbreaking interdisciplinary research on culture, we ought to be envisioning collaboration across languages, literatures, linguistics, the social sciences and the natural sciences. 
The simultaneous liability and possibility afforded by this acute sense of the relativity of language is what informs my negotiations with various levels of English language competence in the English and Western literature classroom. Bilingualism, in my case, is a part-conscious, part-spontaneous, performative strategy in the non-metropolitan literature classroom of an institution that has historically privileged cultural transmission and transaction through the vernacular and which also serves increasingly as an outreach centre for higher studies aspirants from a fairly extensive rural hinterland beyond the political boundaries of West Bengal as a province.

Bilingualism is not an explanatory mode on demand, nor a merely illustrative one. Nor is it a capitulation to classroom populism. I call it performative and strategic, because throwing in the Bangla lyrics of a song by the contemporary Bengali urban rock band in a nonsense literature discussion, or remarking upon how in Birbhum "besh" ("fine"), a more refined version of the Kolkatan words, "achha" ("okay") or "theek achhe" ("all right") is current, or that the word "chikchiki" for plastic bag, or "kaani" for rag, in course of a discussion of how "fond" meant foolish in Shakespeare's English, "brave" meant beautiful, and "clown" was a pejorative for a farmer, are my gradually evolved ways of transforming the classroom into a space and moment where all space- and timezones can converge and mingle. It is my way of contemporanising texts geographically and chronologically distant, of bringing them "home" to myself and those sharing that fertile, epiphanic, magical moment of "recognition" with me. Recognition of sharings amidst the expected difference of cultures and cultural texts far apart in time and place can be a profoundly reassuring humanistic experience. Recognition of difference amidst apparent sameness is far more unsettling, though equally illuminating.

Bilingualism in the classroom is not a means of making a text merely intelligible. In my case, often, the text in question is three times removed from the classroom reality - in English translation, but not originally an English text, and from four five centuries past and a European country. It is not a regular teaching 
aid, so to speak. It is a way of mediating the space between the

student and the text in such a way as to expand it at both ends. It often proves to be a service to the text and its reception beyond literal understanding no less than as a persuasion of the student to enter the text's universe. In a sense, it adds ephemeral, contingent Benjaminian afterlives to the text every day.

The literature classroom is in any case already multilingual, in the sense of our awareness of the impossibility of a pure language, unmediated by the currents of other languages with which it has been historically thrown into contact. No one can read Amitav Ghosh's fiction, particularly The Sea of Poppies, without being impelled to recognise the persistent and irresistible cross-pollination of languages. From Tagore's novella, Shesher Kobita (The Last Poem), to the standard feature story in the Bengali daily Ananda Bazar Patrika's Saturday supplement testifies to the continued currency of bilingualism. Here, I agree with Dipesh Chakrabarty's admission (20-21):

For one of the ironies of attempting to know any kind of language in depth is that the unity of the language is sundered in the process. One becomes aware of how plural a language invariably is, and how it cannot ever be its own rich self except as a hybrid formation of many "other" languages (including, in the case of modern Bengali, English).

However, today, when in the literature classroom I use "juggernaut" or "bandobast", I do so not in a gesture of blind ahistorical appropriation, but in shared awareness of the linguistic cross-fertilisation of all cultural encounter, even one between the coloniser and the colonized. When I use "Zeitgeist" or "Lebensraum" or "Weltanschauung" or "sprezzatura" or "juissance" or "chiaroscuro", I do indeed corroborate Dipesh Chakrabarty's claim (Preface xiii) about neo-colonial educated, middle-class Bengal's modernity being founded upon a provincialisation of the idea of Europe. He calls it the 
the silent and everyday presence of European thought in Indian life and practices. The Enlightenment was part of

my sentiments. Only I did not know it as such. Marx was a household Bengali name. His German upbringing was never commented upon. Bengali scholars translated Das Capital without the slightest hint of any philological concerns. This recognition of a deep-and often unknown - debt to European thought was my point of departure; without that there could be no "provincializing Europe."

But I do so in at least an attempted historicisation of the specific socio-economic and socio-political context that allows both the emergence and propagation of an Italian term or a French phrase or a German one as well as of the caution with which equivalences may be sought from contexts closer home.

At another level, I would submit that all texts from all ages are contemporary anyway, even as they emanate from and engage with a historically specific moment and site. I have always found the factor of pertinence or relevance a curiously unpredictable one. It is eminently possible that Sidney's Arcadia or Sir Thomas More's Utopia speaks to a Santiniketan classroom more vitally than Jhumpa Lahiri's Namesake. It is equally possible that Robert Greene's Coney Catching Pamphlets, written early in the 1590s, with its elaborately laid out para-language of petty crime and its amoral representation of criminal lives and minds should strike a chord of recognition in today's youth in the literature classroom, fed on Bollywood gangster movies.

Philosophically, then, the literature classroom is a Tower of Babel, but a happy one.

\section{REFERENCES}

Benjamin, Walter. Illuminations: Essays and Reflections. Transl. Harry John. Ed. Hannah Arendt. New York: Schocken Books, 1968. Print.

Chakrabarty, Dipesh. Provincializing Europe: Postcolonial Thought and Historical Difference. Princeton: Princeton University Press, 2008. Print. 